
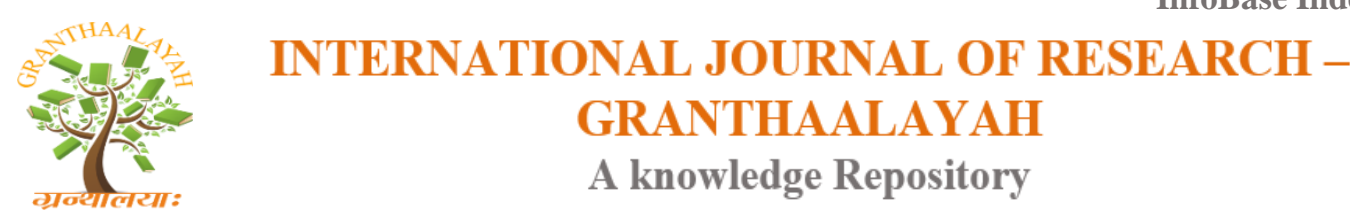

Science

\title{
OPTIMIZATION OF SINGLY REINFORCED RC BEAMS
}

\author{
Stency Mariam Thomas ${ }^{* 1}$, Prince Arulraj. G ${ }^{2}$ \\ ${ }^{* 1}$ PG student, School of Civil Engineering, Karunya University, Coimbatore, Tamil Nadu, India \\ ${ }^{2}$ Professor, School of Civil Engineering, Karunya University, Coimbatore, Tamil Nadu, India
}

DOI: https://doi.org/10.29121/granthaalayah.v5.i2.2017.1724

\begin{abstract}
The main objective of this paper is to achieve an optimal design for the reinforced concrete beams. Optimization of beams results in saving in cost. The objective function is to minimize the total cost of the beam. The cost of each beam includes the cost of concrete, reinforcement and formwork. The optimization process is done for different grades of concrete and steel to determine the best grade of concrete and steel. The optimal design is carried out using MATLAB's (The Mathworks, Inc.) software. Optimization problem is formulated as a Nonlinear constrained minimization problem. This was solved using the fmincon SQP Algorithm. Many problems were solved and it was found that the solutions give the most economical design.
\end{abstract}

Keywords: Optimization; Nonlinear Programming Problem; Constrained Nonlinear Minimization; Matlab; SQP Algorithm.

CITE THIS ARTICLE: Stency Mariam Thomas, and Prince Arulraj. G. (2017). "OPTIMIZATION OF SINGLY REINFORCED RC BEAMS." International Journal of Research - Granthaalayah, 5(2), 199-207. 10.29121/granthaalayah.v5.i2.2017.1724.

\section{Introduction}

Optimization is the process of finding a minimum or maximum value of a function subject to some constraints. Optimization techniques play an important role in structural design, the very purpose of which is to find the best solutions from which a designer or a decision maker can derive a maximum benefit from the available resources. The basic requirement for an efficient structural design is that the response of the structure should be acceptable as per various specifications. There can be large number of feasible designs, but it is desirable to choose the best from these several designs. The best design could be in terms of minimum cost, minimum weight or maximum performance or a combination of these.

In several studies, the optimum cost design of the reinforced concrete (RC) elements has been investigated. Coello et.al.optimized RC beams [1] using a search technique employing genetic algorithm (GA). Ferreira et.al. studied on the optimal design of T-shaped RC beams according to 
various design codes [2]. The simulated annealing algorithm was employed by Leps and Sejnoha to find optimum values of continuous steel reinforced beams [3]. Cost optimization of singly and doubly RC beams was investigated by Barros et.al. [4] Govindaraj and Ramasamy made a detailed investigation on optimum design of RC continuous beams using GA. Different groups of reinforcements were considered to find the solution with the optimum cost [5]. During the present study, optimization of reinforced concrete beam is carried out. The objective function was the total cost of the concrete element which includes the cost of concrete, steel and formwork. Optimization process was done for different grades of concrete and steel and the effect of diameter of rods on optimal cost was also studied. The optimization problem formulated is a Constrained Nonlinear minimization problem and was solved by using fmincon SQP Algorithm of matlab. While framing the constraints, for the design of RC beam elements, it was ensured that all codal provisions of IS 456-2000 were taken into account. Many singly reinforced beams were optimized using the matlab algorithm. The efficiency of the SQP algorithm was examined and found to be good. All the solved problems proved that the results are economical and give minimum construction cost.

\section{Optimal Design of Ric Beams}

The general form of an optimization problem consists of the following steps

1) Identification of design variables

2) Formulation of objective function

3) Formulation of constraints

4) Selection of suitable algorithm

5) Getting solution.

In an optimization problem, some of the parameters can be considered as pre-assigned and others are considered as design variables. The design variables are determined in such a way that the value of an objective function, which is often the cost of the structure, becomes minimum. Some restrictions, called design constraints, may limit the acceptable values of the design variables.

\section{Optimal Design of Singly Reinforced Beams}

\subsection{Constant Parameters}

In this work, optimal design of singly reinforced beam was done for different material combinations of M20, M25, M30, M35, M40, M45grades of concrete and Fe 415, Fe 500,Fe $550 \mathrm{D}$ grades of steel.

The cost of concrete, reinforcement including the cost of bar bending and the cost of formwork were worked out as per the latest market rates and the cost coefficients were worked out for $1 \mathrm{~m}$ length of beam.

The value of cost coefficients for different grades of steel, concrete and for the formwork are given in Table 1. 
Table 1: Values of cost co-efficient

\begin{tabular}{|c|c|c|c|c|}
\hline \multirow[b]{2}{*}{$\begin{array}{l}\text { grade of } \\
\text { concrete }\end{array}$} & \multicolumn{4}{|c|}{ cost coefficient in rupees } \\
\hline & $\begin{array}{l}\text { Cost co- } \\
\text { efficient for } \\
\text { concrete }\end{array}$ & Grade of steel & $\begin{array}{c}\text { Cost co-efficient } \\
\text { for steel }\end{array}$ & $\begin{array}{l}\text { cost co- efficient } \\
\text { for formwork }\end{array}$ \\
\hline M20 & 0.0057 & \multirow{2}{*}{$\mathrm{Fe} 415$} & \multirow{2}{*}{0.43175} & \multirow{6}{*}{0.43} \\
\hline M25 & 0.0065 & & & \\
\hline M30 & 0.0072 & \multirow{2}{*}{$\mathrm{Fe} 500$} & \multirow{2}{*}{0.4687} & \\
\hline M35 & 0.0078 & & & \\
\hline M40 & 0.0084 & \multirow{2}{*}{ Fe550D } & \multirow{2}{*}{0.5119} & \\
\hline M45 & 0.0088 & & & \\
\hline
\end{tabular}

\subsection{Design Variables}

Breadth of the beam, depth of the beam and the area of tension reinforcement were considered as design variables.

Width of beam $=b=x_{1}$

Overall Depth of beam $=\mathrm{d}=\mathrm{x}_{2}$

Area of steel in tension $=$ Ast $=\mathrm{x}_{3}$

\subsection{Objective Function}

The objective function to be minimized is given below:

$\mathrm{f}_{=}\left(\mathrm{x}_{1} * \mathrm{x}_{2}-\mathrm{x}_{3}\right) * \mathrm{C}_{\mathrm{c}}+\mathrm{x}_{3} * \mathrm{C}_{\mathrm{s}}+\left(2 * \mathrm{x}_{2}+\mathrm{x}_{1}\right) * \mathrm{C}_{\mathrm{f}}$

$\mathrm{C}_{\mathrm{c}}-$ cost coefficient of concrete $/ \mathrm{m}$ length of beam

$\mathrm{C}_{\mathrm{s}}$ - cost coefficient of steel $/ \mathrm{m}$ length of beam

$\mathrm{C}_{\mathrm{f}}-$ cost coefficient for formwork $/ \mathrm{m}^{2}$

\subsection{Design Constraints}

i. Maximum reinforcement percentage is incorporated as a constraint as given below $\mathrm{X}_{3} /\left(\mathrm{x}_{1} * \mathrm{X}_{2}\right) \leq 0.04$

ii. Minimum reinforcement percentage is incorporated as a constraint as given below $\mathrm{x}_{3} /\left(\mathrm{x}_{1} * \mathrm{X}_{2}\right) \geq 0.85 / \mathrm{f}_{\mathrm{y}}$

iii. Moment constraints are given below

$\mathrm{Mu} \leq 0.36 * \mathrm{f}_{\mathrm{ck}} * \mathrm{x}_{\mathrm{umax}} \mathrm{b} *\left(\mathrm{~d}-0.42 * \mathrm{x}_{\mathrm{umax}}\right)$

$\mathrm{Mu} \leq 0.87 * \mathrm{f}_{\mathrm{y}} * \mathrm{~A}_{\mathrm{st} *}\left(\mathrm{~d}-0.42 * \mathrm{X}_{\mathrm{umax}}\right)$

$\mathrm{x}_{2} \geq \sqrt{ }\left(\mathrm{Mu} /\left(\mathrm{f}_{\left.\left.\mathrm{ck} * 0.134 * \mathrm{X}_{1}\right)\right)}\right.\right.$

iv. The minimum width of beam is taken as $230 \mathrm{~mm}$

$\mathrm{x}_{1} \geq 230$ 


\subsection{Starting Solution}

Starting solution is nothing but initial point where solver begins its search for a minimum value within the feasible range. The starting solution considered is a scalar which is given below

$\mathrm{x}_{0}=\left[\begin{array}{lll}200200600] & 0\end{array}\right.$

where:

$\mathrm{M}_{\mathrm{u}}=$ Factored Moment

$\mathrm{A}_{\mathrm{st}}=$ Area of longitudinal reinforcement

$\mathrm{f}_{\mathrm{ck}}=$ Characteristic compressive strength of the concrete

$\mathrm{f}_{\mathrm{y}}=$ Characteristic strength of the steel

A matlab program was written using the SQP algorithm available in the matlab tool box.

\subsubsection{Effect of Grade of Concrete}

In order to determine the effect of grade of concrete on the cost of singly reinforced beams, the optimal design of beams was found for various grade of concrete. The details of the optimal designs of beams carrying moments of $75 \mathrm{kNm}, 150 \mathrm{kNm}, 200 \mathrm{kNm}$ and $500 \mathrm{kNm}$ are given in Table 2, Table 3, Table 4 and Table 5 respectively.

Table 2: Optimal results for the beam with a factored moment of $75 \mathrm{kNm}, 150 \mathrm{kNm}, 200 \mathrm{kNm}$ and $500 \mathrm{kNm}$ are given in Table 2, Table 3, Table 4 and Table 5 respectively.

Table 2: Optimal results for the beam with a factored moment of $75 \mathrm{kNm}$

\begin{tabular}{|c|c|c|c|c|}
\hline Grades of concrete & $\mathbf{b}(\mathbf{m m})$ & $\mathbf{d}(\mathbf{m m})$ & Ast $\left.\mathbf{( m m}^{2}\right)$ & Cost/m (Rs) \\
\hline M20 & 230 & 350 & 750 & 1172.51 \\
\hline M25 & 230 & 310 & 840 & 1188.05 \\
\hline M30 & 230 & 280 & 930 & 1199.55 \\
\hline M35 & 230 & 260 & 1000 & 1218.91 \\
\hline M40 & 230 & 245 & 1065 & 1234.37 \\
\hline M45 & 230 & 230 & 1135 & 1243.34 \\
\hline
\end{tabular}

Table 3: Optimal results for the beam with a factored moment of $200 \mathrm{kNm}$

\begin{tabular}{|c|c|c|c|c|}
\hline grades of concrete & $\mathbf{b}(\mathbf{m m})$ & $\mathbf{d}(\mathbf{m m})$ & $\left.\mathbf{A s t} \mathbf{( m m}^{\mathbf{2}}\right)$ & $\mathbf{C o s t} / \mathbf{m}(\mathbf{R s})$ \\
\hline M20 & 230 & 490 & 1065 & 1617.39 \\
\hline M25 & 230 & 440 & 1185 & 1638.97 \\
\hline M30 & 230 & 400 & 1305 & 1655.63 \\
\hline M35 & 230 & 370 & 1400 & 1683.01 \\
\hline M40 & 230 & 345 & 1500 & 1704.87 \\
\hline M45 & 230 & 325 & 1600 & 1717.56 \\
\hline
\end{tabular}


Table 4: Optimal results for the beam with a factored moment of $200 \mathrm{kNm}$

\begin{tabular}{|l|l|l|l|l|}
\hline grades of concrete & $\mathbf{b}(\mathbf{m m})$ & $\mathbf{d}(\mathbf{m m})$ & Ast $\left.\mathbf{( m m}^{\mathbf{2}}\right)$ & Cost/m $(\mathbf{R s )}$ \\
\hline M20 & 230 & 580 & 1200 & 1852.37 \\
\hline M25 & 230 & 500 & 1390 & 1877.29 \\
\hline M30 & 230 & 465 & 1500 & 1896.53 \\
\hline M35 & 230 & 430 & 1620 & 1928.14 \\
\hline M40 & 230 & 400 & 1750 & 1953.38 \\
\hline M45 & 230 & 375 & 1855 & 1968.03 \\
\hline
\end{tabular}

Table 5: Optimal results for the beam with a factored moment of $500 \mathrm{kNm}$

\begin{tabular}{|c|c|c|c|c|}
\hline grades of concrete & b (mm) & d (mm) & $\operatorname{Ast}\left(\mathbf{m m}^{2}\right)$ & Cost/m (Rs) \\
\hline M20 & 230 & 900 & 1930 & 2871.63 \\
\hline $\mathrm{M} 25$ & 230 & 800 & 2175 & 2911.04 \\
\hline M30 & 230 & 735 & 2360 & 2941.45 \\
\hline M35 & 230 & 680 & 2560 & 2991.43 \\
\hline M40 & 230 & 635 & 2735 & 3031.35 \\
\hline
\end{tabular}

From the results obtained, it can be concluded that M20 grade concrete is preferred as it gives the least cost. It can be seen that lower grade concrete results in larger depths, lower area of steel and least cost. Hence, lower grade concrete can be preferred wherever depth restriction is not a criterion for the design.

\subsubsection{Effect of Diameter of Reinforcement on the Cost of Beams}

Designers normally determine $\mathrm{A}_{\mathrm{st}}$ and determine the number of rods assuming the diameter of rods. In case of beams, the designers can select the diameter from a set of $\{12$, $16,20,25,32,40 \mathrm{~mm}\}$ which are available in the market. Only one of them will give the least cost.

In order to determine the optimal diameter of reinforcement, the optimal design of beams were carried out for various diameters of reinforcement.

The details of the optimal design for the beam with a factored moment of $75 \mathrm{kNm}$ are given in Table 6.

Table 6: Effect of diameter of reinforcement on optimal cost of beam with a moment of $75 \mathrm{kNm}$

\begin{tabular}{|l|l|l|l|l|}
\hline Diameter (mm) & 12 & 16 & 20 & 25 \\
\hline No of bars & 7 & 4 & 3 & 2 \\
\hline Area provided (mm2) & 791.68 & 804.25 & 942.48 & 981.75 \\
\hline Cost/m (Rs) & 1196.05 & 1201.40 & 1260.29 & 1277.02 \\
\hline
\end{tabular}


It can be seen from the Table that $12 \mathrm{~mm}$ diameter of reinforcement gives the least area. Therefore, providing $12 \mathrm{~mm}$ diameter rod will give the least cost. When $25 \mathrm{~mm}$ diameter rods are used, the percentage increase with respect to least cost is around $6.7 \%$

The details of the optimal design for the beam with a factored moment of $150 \mathrm{kNm}$ are given in Table 7.

Table 7: Effect of diameter of reinforcement on optimal cost of beam with a moment of $150 \mathrm{kNm}$

\begin{tabular}{|l|l|l|l|l|}
\hline Diameter (mm) & 16 & 20 & 25 & 32 \\
\hline No of bars & 6 & 4 & 3 & 2 \\
\hline Area provided $\left.\mathbf{( m m}^{\mathbf{2}}\right)$ & 1206.37 & 1256.64 & 1472.62 & 1608.49 \\
\hline Cost/m (Rs) & 1676.66 & 1698.08 & 1790.10 & 1847.99 \\
\hline
\end{tabular}

It can be seen from the Table that $16 \mathrm{~mm}$ diameter of reinforcement gives the least area. Therefore, providing $16 \mathrm{~mm}$ diameter rod will give the least cost. When $32 \mathrm{~mm}$ diameter rods are used, the percentage increase with respect to least cost is around $10.21 \%$.

The details of the optimal design for the beam with a factored moment of $200 \mathrm{kNm}$ are given in Table 8 .

Table8: Effect of diameter of reinforcement on optimal cost of beam with a moment of $200 \mathrm{kNm}$

\begin{tabular}{|l|l|l|l|l|}
\hline Diameter (mm) & 16 & 20 & 25 & 32 \\
\hline No of bars & 6 & 4 & 3 & 2 \\
\hline Area provided $\left(\mathbf{m m}^{\mathbf{2}}\right)$ & 1206.4 & 1256.6 & 1472.62 & 1608.941 \\
\hline Cost/m (Rs) & 1872.1 & 1893.5 & 1985.49 & 2043.569 \\
\hline
\end{tabular}

It can be seen that $16 \mathrm{~mm}$ diameter of reinforcement gives the least area. Therefore, providing $16 \mathrm{~mm}$ diameter rod will give the least cost. When $32 \mathrm{~mm}$ diameter rods are used, the percentage increase with respect to least cost is around $9.15 \%$

The details of the optimal design for the beam with a factored moment of $500 \mathrm{kNm}$ are given in Table 9.

Table 9: Effect of diameter of reinforcement on optimal cost of beam with a moment of 500kN

\begin{tabular}{|l|l|l|l|l|}
\hline Diameter (mm) & 20 & 25 & 32 & 40 \\
\hline No of bars & 7 & 4 & 3 & 2 \\
\hline Area provided (mm2) & 2199.11 & 1963.49 & 2412.74 & 2513.27 \\
\hline Cost/m (Rs) & 2989.73 & 2889.35 & 3080.75 & 3123.58 \\
\hline
\end{tabular}

It can be seen that $25 \mathrm{~mm}$ diameter of reinforcement gives the least area. Therefore, providing $16 \mathrm{~mm}$ diameter rod will give the least cost. 


\section{Effect of Grade of Steel on Cost of Beam}

In order to study the effect of grade of steel on the cost of beam, optimal designs were found for various grades of steel. The grade of concrete assumed was M20.The optimization was done with $\mathrm{Fe} 415, \mathrm{Fe} 500$ and Fe 550D grades of steel. Even though IS 456-2000 permits the use of only three grades namely $\mathrm{Fe} 250, \mathrm{Fe} 415$ and Fe500, Fe 550D which has a higher ductility is also tried, since Fe550D is included in IS 1786-2008and it satisfies the ductility requirements with enhanced benefits.

The details of beams with different factored moments designed with Fe415 rods are given in Table 10.

Table 10: Design details with Fe 415 rods

\begin{tabular}{|c|c|c|c|}
\hline Moment (kNm) & $\mathrm{d}(\mathrm{mm})$ & $\operatorname{Ast}\left(\mathrm{mm}^{2}\right)$ & $\operatorname{Cost} / \mathrm{m}(\mathrm{Rs})$ \\
\hline 75 & 350 & 750.00 & 1172.51 \\
\hline 100 & 400 & 860.00 & 1338.67 \\
\hline 125 & 450 & 965.00 & 1485.05 \\
\hline 150 & 490 & 1065.00 & 1617.39 \\
\hline 200 & 580 & 1200.00 & 1852.37 \\
\hline 250 & 630 & 1380.00 & 2059.39 \\
\hline 300 & 700 & 1500.00 & 2246.55 \\
\hline 400 & 850 & 1640.00 & 2578.86 \\
\hline 500 & 900 & 1930.00 & 2871.63 \\
\hline
\end{tabular}

The details of beams with factored moments designed with Fe500 rods are given in Table 11.

Table 11: Design details with Fe 500 rods

\begin{tabular}{|l|l|l|l|}
\hline Moment (kNm) & d (mm) & Ast $\left.\mathbf{( m m}^{\mathbf{2}}\right)$ & Cost/m $(\mathbf{R s )}$ \\
\hline 75 & 350 & 610.40 & 1139.14 \\
\hline 100 & 400 & 704.84 & 1300.14 \\
\hline 125 & 450 & 788.03 & 1441.98 \\
\hline 150 & 500 & 863.25 & 1570.21 \\
\hline 200 & 575 & 996.79 & 1797.89 \\
\hline 250 & 640 & 1114.44 & 1998.48 \\
\hline 300 & 700 & 1220.82 & 2179.82 \\
\hline 400 & 800 & 1409.68 & 2501.81 \\
\hline 500 & 931 & 1576.07 & 2785.49 \\
\hline
\end{tabular}

The details of beams with factored moments designed with Fe550D rods are given in Table 12.

Table 12: Design details with Fe 550D rods

\begin{tabular}{|c|c|c|c|}
\hline Moment $\mathbf{( k N m )}$ & $\mathbf{d}(\mathbf{m m})$ & $\left.\mathbf{A s t} \mathbf{( m m}^{\mathbf{2}}\right)$ & $\mathbf{C o s t} / \mathbf{m} \mathbf{( R s )}$ \\
\hline 75 & 356.11 & 539.91 & 1142.87 \\
\hline 100 & 411.2 & 623.44 & 1304.44 \\
\hline 125 & 459.745 & 697.02 & 1446.78 \\
\hline
\end{tabular}




\begin{tabular}{|c|c|c|c|}
\hline 150 & 503.62 & 763.55 & 1575.47 \\
\hline 200 & 581.53 & 881.67 & 1803.97 \\
\hline 250 & 650.17 & 985.73 & 2005.28 \\
\hline 300 & 712.23 & 1079.82 & 2187.27 \\
\hline 400 & 822.41 & 1246.87 & 2510.41 \\
\hline 500 & 919.49 & 1394.04 & 2795.10 \\
\hline
\end{tabular}

From Tables 10, 11 and 12, it is observed that Fe 500 grade steel and yields the optimum design values for the singly reinforced beam with least cost. The percentage reduction in cost when Fe 500 steel is around $3 \%$ with respect to $\mathrm{Fe} 415$ steel.

\section{Conclusions}

The main conclusions drawn from the current research can be summarized as follows:

- The efficiency of the SQP algorithm optimization was examined and found to be good.

- Optimization of reinforced concrete beams indicate that minimum percentage of steel must be used as reinforcement. Higher percentage of steel results in higher cost.

- The effect of grade of concrete on the cost of beams was studied and it was found that grade of concrete has an impact on the cost of R.C beams. M20 grade of concrete is found to give least cost.

- The effect of grade of steel on the cost of beams was studied and it was found that grade of steel has an impact on the cost of R.C beams. Fe 500 grade of steel is found to give least cost.

- The effect of diameter of reinforcement on the cost of beam were also studied and it was found that diameter of concrete has an impact on the cost of reinforced concrete beams. Instead of selecting the diameter of the reinforcement arbitrarily, diameter has to be found through optimization.

\section{Acknowledgement}

The authors are thankful to the management of Karunya University for providing necessary facilities to carry out the work reported in this paper.

\section{References}

[1] Coello.C.C, Hernandez F.S and Farrera F. A, Optimal Design of Reinforced Concrete Beams Using Genetic Algorithms, Expert Systems with Applicatons, Vol. 12, 1997, pp. 101-108.

[2] Ferreira.C.C,. Barros. M. H. F. M and Barros A. F. M, Optimal design of reinforced concrete TSections in Bending, Engineering Structures,Vol. 25, 2003, pp. 951-964.

[3] Leps M and Sejnoha M., New Approach to Optimization of Reinforced Concrete Beams, Computers and Structures, Vol.81, 2003, pp- 1957-1966.

[4] Barros M. H. F. M, Martins R. A. F and Barros A. F. M., Cost optimization of Singly and Doubly Reinforced Concrete Beams with EC2-2001, Structural and Multidisciplinary Optimization, Vol. 30, 2005, pp-236-242. 
[5] Govindaraj.V and Ramasamy.J. V, Optimum Detailed Design of Reinforced Concrete Continuous Beams Using Genetic Algorithms, Computers and Structures, Vol. 84, 2005, pp- 34-48.

[6] IS 456:2000 - Plain and Reinforced Concrete - Code of Practice, Bureau of Indian Standards, Manak Bhavan, New Delhi.

[7] IS 1786:2008- High Strength Deformed Stee Bars and Wires for Concrete ReinforcementSpecification

*Corresponding author.

E-mail address: stencymariamthomas10@gmail.com 